\title{
Removal of temporary pacemaker after cardiac surgery in infants: A harmless procedure?
}

\author{
Stephan Schoof ${ }^{\mathrm{a}}$, Harald Bertram ${ }^{\mathrm{a}}$, Jan Thommes ${ }^{\mathrm{a}}$, Thomas Breymann ${ }^{\mathrm{b}}$, Urte Grosser ${ }^{\mathrm{a}}$, \\ T. Mesud Yelbuz ${ }^{\mathrm{a}}$, Armin Wessel ${ }^{\mathrm{a}}$ and Kambiz Norozi ${ }^{\mathrm{a}, \mathrm{c}, *}$ \\ ${ }^{a}$ Department of Pediatric Cardiology and Intensive Care Medicine, Medical School Hannover, Germany \\ ${ }^{\mathrm{b}}$ Division of Thoracic and Cardiovascular Surgery, Hannover Medical School, Hannover, Germany \\ ${ }^{\mathrm{c}}$ Division of Pediatric Cardiology, Department of Pediatrics, London Health Sciences Centre, London, ON, Canada
}

Received 8 January 2011

Revised 3 April 2011

Accepted 2 May 2011

\begin{abstract}
External pacemakers (PM) via temporary epicardial leads are routinely applied to infants and children during heart surgery, which usually, after an uneventful post surgical course, can be removed without complications. We report about two infants with complex congenital heart defects after cardiac surgery (arterial switch and Mustard operation for Transposition of the great arteries). Intraoperative these patients received temporary epicardial PM wires. Thirteen and 18 days post surgery, respectively, the PM wires were removed under electrocardiogram (ECG) monitoring. The patients showed acute ECG changes in terms of significant ST elevation during and after removing their pacing wires. Clinically, patients were stable and subsequent echocardiographic examination showed no evidence of myocardial dysfunction or pericardial effusion. In the course of time, patients showed no signs of arrhythmia or abnormal ECG changes. The decision to place temporary pacing wires during the cardiac surgery in patients with congenital heart defects should be considered carefully and their removal should occur under ECG monitoring as soon as the situation of the patient allows. It should be taken into consideration that a complication like this case may be related to delayed removal of temporary PM's leads.
\end{abstract}

Keywords: Congenital heart disease, pacemaker, vascular tone and reactivity, arrhythmia

\section{Introduction}

Malformations of the heart (congenital heart disease) are the most common congenital birth defects, occurring in about $1 \%$ of children [1] and the vast majority of them need cardiac surgery. The cardiac rhythm in the early postoperative period after open-heart surgery is very labile and more prone to arrhythmias. Factors that lead

*Corresponding author: Kambiz Norozi, Division of Pediatric Cardiology, Department of Pediatrics, London Health Sciences Centre, 800 Commissioners Rd E, PO Box 5010, London, Ontario, Canada, N6A 5W9, Tel.: +1 5196858500 ext. 56062; Fax: +1 519 685 8156; E-mail: kambiz.norozi@1hsc.on.ca. to arrhythmias at this time include the scars of surgery, damage to the sinus or atrioventricular node, electrolyte shifts, exogenous and endogenous catecholamines, myocardial stretch and drug therapy for other problems. These facts lead in most cases to implant external pacemakers (PM) via temporary epicardial leads, which usually can be removed in the first two weeks (up to 6 weeks) postoperatively [2].

External PM via temporary epicardial leads are routinely applied to infants and children during heart surgery, which usually, after an uneventful post surgical course, can be removed without complications in the first two weeks postoperatively. There are few reports 
about arrhythmias during removal of temporary pacing wires in adult patients $[3,4]$; to the best of our knowledge, there is no similar report about the electrocardiogram (ECG) changes, i.e. ST elevation, while pulling out the temporary pacing wires after cardiac surgery in infants.

\section{Case report}

We report about two infants with complex congenital heart defects who were admitted in our institute for cardiac surgery (Table 1). After successful heart surgery and before ending of extra corporal circulation, the standard temporary epicardial PM wires were used with the recommended implantation techniques in all patients. Two temporary epicardial pacing wires (TME 68 TVL bifurcated; Osypka; Rheinfelden, Germany) with $5.0 \mathrm{~mm}$ of exposed electrode surface area were placed onto the ventricular myocardium using 6.0 Prolene single suture technique. Likewise, two atrial temporary cardiac pacing electrodes with enough wire loops at the cardiac end were placed on the atrial myocardium. The ventricular pacing wires were inserted onto the right ventricular free wall, and the atrial pacing wires were sutured to the right atrial free wall.

The temporary pacemaker wires (both ventricular and atrial wires simultaneously) were removed at day 13 and 18, respectively, after operation under ECG monitoring and Holter ECG. The reason for relatively late removal of pacemaker wires was delayed patient's recovery due to complexity of cardiac defects and their surgical repair. During and after pulling out of their pacing wires, both patients showed temporary acute ECG changes in terms of ST elevation (Fig. 1). The ECG changes persisted only 2 and $7 \mathrm{~min}$, respectively. Clinically, both patients were stable and subsequent echocardiographic examination showed no evidence of myocardial dysfunction or pericardial effusion. In the course of time, patients showed no signs of arrhythmia or abnormal ECG changes. In one case (patient 2), the myocardial enzyme creatine kinase (CK and CK-MB), and cardiac troponin $\mathrm{T}(\mathrm{cTnT})$ were determined before and $12 \mathrm{~h}$ post PM removal. Neither CK nor CK-MB showed a significant increase (CK: $26 \mathrm{U} / \mathrm{L}$ and $34 \mathrm{U} / \mathrm{L}$; CK-MB: $16 \mathrm{U} / \mathrm{L}$ and $22 \mathrm{U} / \mathrm{L}$, respectively). However, we observed a slight increase in serum cTnT level to $0.08 \mu \mathrm{g} / \mathrm{L}$ (normal range $<0.04 \mu \mathrm{g} / \mathrm{L}$ ). In both cases, the inflammatory parameters (e.g. C-reactive protein), cardiac markers and ECG's were obtained prior to removal of PM wires and all showed no abnormalities.

The video file, extracted from Holter ECG, shows the ECG changes of patient number 1 during removal of pacing wires.

\section{Discussion}

There have been numerous complications described concerning temporary epicardial pacing wires including arrhythmias [4], infection [5] and bleeding [6] resulting in cardiac tamponade and hemodynamic decompensation. Unusual complications, including pacing wires ensnaring the heart and causing hemodynamic decompensation during attempted removal have been reported in children [7]. To the best of our knowledge, there is no similar report about the ECG changes, i.e. ST elevation, while pulling out the temporary pacing wires after cardiac surgery in infants.

The cause of ECG changes in our patients remains speculative. One possible explanation is the epicardial irritation during this maneuver. The second possibility is the temporary vasoconstriction of coronary arteries causing myocardial ischemia due to mechanical manipulation and movement of the heart while pulling out the PM wires. The slightly increased serum cTnT without CK increasing led to the interpretation that in this situation temporary myocardial ischemia could be responsible for ST elevation in ECG and cTnT release. Adherence of PM wires to the epicardial surface could be exacerbated by delayed wire removal. To prevent this condition our surgeons reduced the loops while placing PM wires

Table 1

Characteristics of patients

\begin{tabular}{lccccc}
\hline Patients & Diagnosis & $\begin{array}{c}\text { Type of } \\
\text { operation }\end{array}$ & $\begin{array}{c}\text { Age at } \\
\text { operation }\end{array}$ & $\begin{array}{c}\text { Weight at } \\
\text { operation }\end{array}$ & $\begin{array}{c}\text { Pacemakers } \\
\text { removal }\end{array}$ \\
\hline Patient 1 & $\begin{array}{c}\text { Transposition of the } \\
\text { great arteries, } \\
\text { cardiogram changes }\end{array}$ & Arterial switch & 12 days & $3.5 \mathrm{~kg}$ & $\begin{array}{c}\text { Day 13 post } \\
\text { operative }\end{array}$ \\
Patient 2 & $\begin{array}{c}\text { Transposition of the } \\
\text { great arteries }\end{array}$ & $\begin{array}{c}\text { Atrial switch } \\
\text { (Mustard) }\end{array}$ & 10 days & $4.5 \mathrm{~kg}$ & $\begin{array}{c}\text { Day } 18 \text { post } \\
\text { operative }\end{array}$ \\
\hline
\end{tabular}



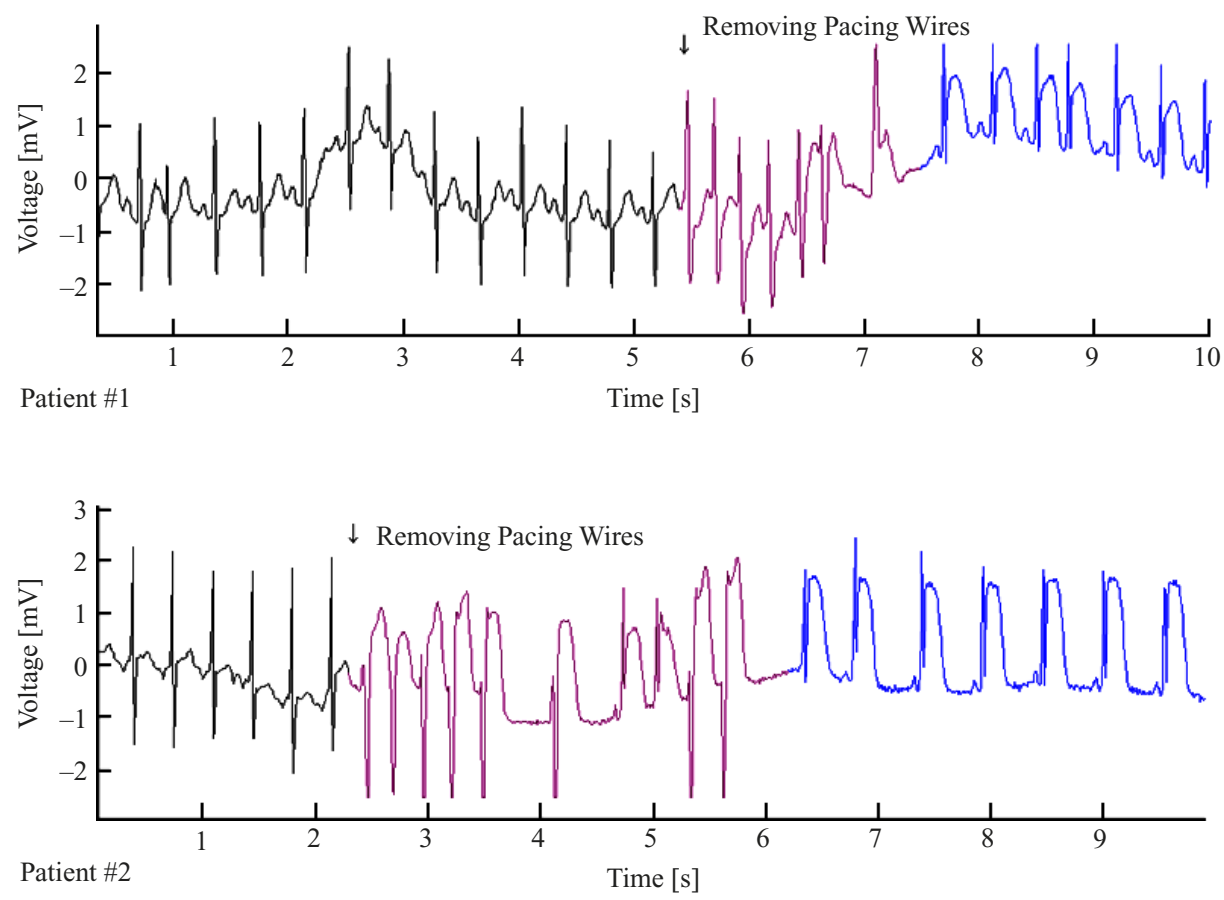

Fig. 1. The electrocardiogram of patients number 1 and 2 before, during and after removal of pacing wires. The violet marked sequence indicates extra systoles during removal of pacing wires. The blue marked sequence shows dramatic ST elevation short after removal of pacing wires.

on the myocardium (using the same wires as before), and we removed the PM wires as soon as the condition of our patients allowed to do so (mostly before day 5 post operative). With these measures, we observed further ECG changing during the removal of PM wires. Recently, Fishberger et al. [8] demonstrated the low incidence of postoperative cardiac arrhythmia in patients with congenital heart defects and came to conclusion that the rare occurrence of arrhythmias supports the approach of selective placement of temporary pacing wires. In light of our observations, we do agree with this recommendation. It should be taken into consideration that a complication like this case can occur when timing of temporary lead removal is delayed for some reason.

In conclusion, the decision to place the temporary pacing wires during the cardiac surgery in patients with congenital heart defects should be considered carefully, and their removal should occur under ECG monitoring as soon as the situation of the patient allows.

\section{Acknowledgements}

We thank Judith Misske for the collection of data.

\section{References}

[1] Hoffman JI, Kaplan S. The incidence of congenital heart disease. J Am Coll Cardiol 2002;39(12):1890-1900.

[2] Janousek J, Vojtovic P, Chaloupecký V, Hucín B, Tláskal T, Kostelka M, et al. Hemodynamically optimized temporary cardiac pacing after surgery for congenital heart defects. Pacing Clin Electrophysiol 2000;23(8):1250-9.

[3] Carroll KC, Reeves LM, Andersen G, Ray FM, Clopton PL, Shively M, et al. Risks associated with removal of ventricular epicardial pacing wires after cardiac surgery. Am J Crit Care 1998;7(6):444-9.

[4] Imren Y, Zor H, Tasoglu I. Ventricular fibrillation following removal of temporary epicardial pacemaking wires. Cardiol Young 2005;15(6):654-5.

[5] Kanoh M, Ishikawa S, Suzuki M, Otaki A, Takahashi T, Satoh Y, et al. Postoperative infections related to pacing wires, pulmonary arterial catheters, and drainage tubes temporarily inserted during open-heart surgery. Jpn J Thorac Cardiovasc Surg 1998;46(2):170-4 (in Japanese).

[6] Dougenis D, Dark JH, Gold RG. Perforation of the left ventricle by a temporary pacing lead. Intensive Care Med 1990;16(8):520-1.

[7] Bolton JW, Mayer JE Jr. Unusual complication of temporary pacing wires in children. Ann Thorac Surg 1992;54(4): 769-70.

[8] Fishberger SB, Rossi AF, Bolivar JM, Lopez L, Hannan RL, Burke RP. Congenital cardiac surgery without routine placement of wires for temporary pacing. Cardiol Young 2008; 18(1):96-9. 